\title{
THE 'TRICKY DANCE' OF ADVOCACY: A STUDY OF NON-LEGAL MENTAL HEALTH ADVOCACY
}

\author{
WANDA BENNETTS, CHRIS MAYLEA, BRIAN MCKENNA, AND HELEN MAKREGIORGOS*
}

\begin{abstract}
Advocacy in compulsory mental health settings is complex and contested, incorporating legal, non-legal, representational and best interests advocacy. This paper presents an approachto non-legal representational advocacy used by Independent Mental Health Advocacy (IMHA), in Victoria, Australia, drawing on in-depth qualitative interviews with advocates and other key stakeholders. After outlining the Victorian context and the IMHA model, this paper shows how IMHA privileges the consumer voice using representational advocacy, which is rights-based and works for systemic change. Using a supported decision-making model, the paper highlights the enablers and challenges which exist, before discussing the implications in terms of rights, power, capacity building and systemic change. The participants saw IMHA as working to address one of the most troubling tensions in mental health care, between the perceived need for coercion and the need to support people to make their own decisions. Representational advocacy provides a clear, easily transferable and tested framework for engaging in supported decision-making processes with people in the mental health system.
\end{abstract}

Keywords: IMHA; Independent Mental Health Advocacy; mental health; advocacy; Victoria Australia; non-legal advocacy; compulsory treatment; involuntary treatment; supported decision-making

\section{INTRODUCTION}

Advocacy in compulsory mental health settings is a complex and contested affair, incorporating legal, non-legal, representational and best interests advocacy with a raft of other concepts in diverse contexts. ${ }^{1}$ For many who are subject to compulsory treatment, the experience is frightening, disempowering and can lead to lasting trauma, and advocacy can offer a supportive and empowering salve to distress. For decades, debate has raged between those who prioritise the 'rights' of consumers - often lawyers, and those who prioritise their 'interests' - often psychiatrists. ${ }^{2}$ Over time, this debate has evolved into a complex and nuanced dialog, with mental health legislation across the globe taking away people's right to make their own decisions, while seeking to protect their right to participate in those decisions. This occurs with both legal and non-legal advocates trying to balance rights to health, to personal and community

\footnotetext{
* Wanda Bennetts, Senior Consumer Consultant, Independent Mental Health Advocacy, Chris Maylea, Lecturer, RMIT University, Brian McKenna, Professor in Forensic Mental Health, Auckland University of Technology and the Auckland Regional Forensic Psychiatry Services, Helen Makregiorgos, Manager, Independent Mental Health Advocacy.

${ }^{1}$ Fleur Beaupert, 'Mental Health Tribunal Processes and Advocacy Arrangements: "Little Wins" Are No Small Feat' (2009) 16(1) Psychiatry, Psychology and Law [90]; Julie Ridley et al, Independent Mental Health Advocacy - The Right to Be Heard: Context, Values and Good Practice (Jessica Kingsley Publishers, 2015); Eleanore Fritze, 'Shining a Light behind Closed Doors' (Victorian Legal Aid, 2015).

${ }^{2}$ Alan A Stone, 'The Myth of Advocacy' (1979) 30(12) Psychiatric Services [819].
} 
safety, to self-determined recovery and to dignity. We argue that advocacy can play a key role in balancing or resolving this tension.

This tension is perhaps best encapsulated in the limited application of the United Nations Convention on the Rights of Persons with Disabilities ${ }^{3}$ (CRPD), which upholds the right of people to be supported in making their own decisions. The independent expert Committee on the Convention ${ }^{4}$ has interpreted this to mean that people cannot be forced to receive treatment. ${ }^{5}$ However, this has not resulted in a worldwide ban on compulsory treatment, on the contrary. Australia, for example, ratified the Convention, while declaring that it understands 'the Convention allows for compulsory assistance or treatment of persons, including measures taken for the treatment of mental disability...${ }^{\prime}$ As is to be expected, all Australian States and Territories have mental health legislation which allows for people who meet certain criteria to receive compulsory treatment, but only two, Victoria and Western Australia, have independent representational non-legal advocacy. ${ }^{7}$ This represents a shift away from a purely substituted decision-making regime, where professionals assume decision-making responsibility based on a perception of the inability of the person to make 'good' decisions. The shift is towards a rights based representational advocacy approach, where professionals assist people to make whatever decisions they can, using supported decision-making approaches.

This paper presents an approach to non-legal representational advocacy that describes the application of this model within the Victorian context, drawing on in-depth qualitative interviews with advocates and other key stakeholders. This is not an evaluation of this model or its impact, but rather a descriptive illustration of its intent and approach.

\section{NON-LEGAL REPRESENTATIONAL ADVOCACY IN MENTAL HEALTH}

Historically, people receiving compulsory mental health treatment have been subject to the 'myth of incompetence's, and 'silenced on the grounds of irrationality'. ${ }^{9}$ Mental

${ }^{3}$ (United Nations [UN] 2515 UNTS 3, UN Doc A/Res/61/106, Annex, GAOR 61 ${ }^{\text {st }}$ Session Supp 49, 65. (Adopted) 13 Dec 2006, (Opened for Signature) 30 May 2007, [Entered Into Force] 3 May 2008.

${ }^{4}$ Established virtue of Article 34 of the Convention.

${ }^{5}$ Christopher Maylea and Asher Hirsch, 'The Right to Refuse: The Victorian Mental Health Act 2014 and the Convention on the Rights of Persons with Disabilities' (2017) 42(2) Alternative Law Journal [149]; Tina Minkowitz, 'Prohibition of Compulsory Mental Health Treatment and Detention Under the CRPD' (SSRN Scholarly Paper ID 1876132, Social Science Research Network, 30 June 2011, http://papers.ssin.com/abstract=1876132)

${ }^{6}$ Convention on the Rights of Persons with Disabilities Declaration 2009 (Cth) Sch 2. Instrument of Ratification.

${ }^{7}$ Chris Maylea et al, 'Review of the Independent Mental Health Advocacy Service (IMHA)' (Centre for Applied Social Research, RMIT University, 2017).

${ }^{8}$ Lawrence O Gostin, Lance Gable, 'Global Mental Health: Changing Norms, Constant Rights' (2008) 9(1) Georgetown Journal of International Affairs 83, [84].

${ }^{9}$ Karen Newbigging et al, 'Right to Be Heard, A Review of Independent Mental Health Advocacy Services in England (Research Report, University of Central Lancashire, June 2012), [20].

<https://www.uclan.ac.uk/research/explore/projects/assets/mental_health_wellbeing_review_of_indepe ndent_mental_health_advocate_research_report_190612.pdf >. 
health advocacy seeks to address this by giving voice to people subject to compulsory treatment. With origins in the consumer movement, ${ }^{10}$ and links to concepts such as supported decision-making and recovery-oriented practice, mental health advocacy seeks to ensure that the rights of people subject to compulsory treatment are maintained, and that they are, in so much as is possible within legislative frameworks, involved in decisions about their treatment, care and recovery. Foley and Platzer define advocacy as:

... any action to assure the best possible services or intervention in the service system on behalf of an individual or group. Specifically, advocacy is the activity of an individual to pursue and act in the interests of another, where the latter defines his or her own interests and through the process of advocacy gains a certain degree of power to pursue them. ${ }^{11}$

In the mental health context, non-legal advocacy is focused on establishing, protecting and maintaining a person's fundamental rights, including rights to choose and refuse treatment, freedom of movement, communication, due process and to full participation in society. These rights have not been consistently maintained by mental health services, ${ }^{12}$ and independent advocates play an important part in ensuring that clinical considerations are balanced with a person's rights. Stomski et al. highlight four main ways in which this is done in non-legal mental health advocacy:

negotiating on behalf of consumers during meetings with health professionals; liaising between consumers and health professionals outside of meetings; supporting consumer decision-making without the involvement of health professionals; and involvement in legal processes. ${ }^{13}$

Legal advocacy, conversely, focuses on Tribunal representation, appeals, and is often means or merits tested. ${ }^{14}$ Representational advocacy has been defined as advocacy which:

ensures that people are supported to speak for themselves and have someone 'on their side' who can represent their views, wishes and concerns. Advocates take their instruction from the [Patient] and ensure that they do not take action without the [Patient's] express permission. Representational (or instructed) advocacy promotes what the [Patient] wants for his or herself not what other people think they should have or not have. ${ }^{15}$

The central role of the non-legal representational mental health advocate is to give voice to the person subject to compulsory treatment in negotiating the infringements on their rights. In this way, the notion of advocacy relies on the idea that people who

${ }^{10}$ Janet Wallcraft, J Read and Angela Sweeney, On Our Own Terms: Users and Survivors of Mental Health Services Working Together for Support and Change (2003).

${ }^{11}$ Ronan Foley and Hazel Platzer, 'Place and Provision: Mapping Mental Health Advocacy Services in London' (2007) 64(3) Social Science \& Medicine 617, [618].

12 Kathleen M Griffiths, John Mendoza and Bradley Carron-Arthur, 'Where to Mental Health Reform in Australia: Is Anyone Listening to Our Independent Auditors?' (2015) 202(4) The Medical Journal of Australia, [172].

${ }^{13}$ Norman Stomski et al, 'Advocacy Processes in Mental Health: A Qualitative Study' (2017) 14(2) Qualitative Research in Psychology 200, [200].

${ }^{14}$ Fleur Beaupert et al, 'Advocacy and Participation in Mental Health Cases : Realisable Rights or PipeDreams?' (2008) 26(2) Law in Context [125].

${ }^{15}$ Maylea and Hirsch, above $\mathrm{n} 5$. 
are receiving services should be in control of decisions regarding their treatment and recovery, or at the very least be involved in decisions about their treatment.

Respect for an individual's autonomy has historically not been upheld in the mental health context, when people may struggle to make decisions due to their experiences of mental distress, constraints of statutory and risk-based practice frameworks, or other cognitive, social or functional barriers.

Despite these barriers, consumers of mental health services have consistently identified autonomy as a vital aspect of recovery. ${ }^{16}$ Eades writes; 'Through autonomous action we demonstrate that we are empowered and that we have a sense of self, which we value. $^{17}$

A growing understanding of the importance of supporting autonomy for people in a mental health setting has resulted in a variety of approaches to decision-making, represented as a continuum in Figure 1:

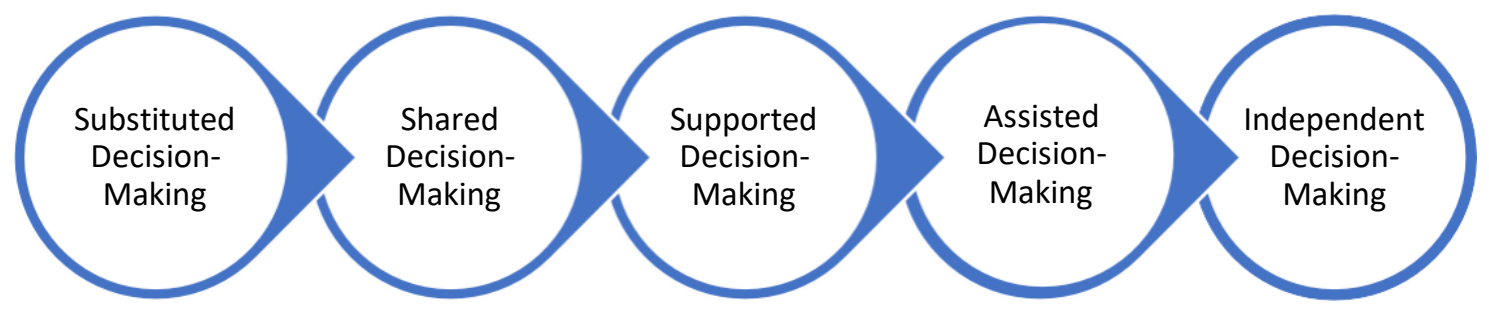

Figure 1 - A continuum of decision-making

Most decisions people make about treatment require some form of assistance, if only in the form of information from expert professionals. Consequently few decisions are purely independent, uninfluenced by social norms or advice from experts. In this way, most decisions made by people will engage in independent or rather assisted decisionmaking to exercise their autonomy.

In a mental health context, people may require support to exercise their autonomy. Autonomy can be understood as an interactive but self-determined position, where

${ }^{16}$ Fauzia Knight et al, 'Supported Decision-Making: The Expectations Held by People With Experience of Mental Illness' [2018] Qualitative Health Research 1049732318762371; Louise Byrne, Stephanie Schoeppe and Julie Bradshaw, 'Recovery without Autonomy: Progress Forward or More of the Same for Mental Health Service Users?' [2018] International Journal of Mental Health Nursing; Patricia Deegan, 'Recovery as a Journey of the Heart' (1996) 19(3) Psychiatric Rehabilitation Journal[91].

${ }^{17}$ Susan Eades, 'Impact Evaluation of an Independent Mental Health Advocacy (IMHA) Service in a High Secure Hospital: A Co-Produced Survey Measuring Self-Reported Changes to Patient Self-Determination' (2018) 22(1) Mental Health and Social Inclusion[53]. 
people maintain ownership and control over decisions that affect their lives. ${ }^{18}$ Supported decision-making supports the right of people to achieve autonomy, with a structured process to assist people in making their own decisions. ${ }^{19}$ This may include assisting with small steps of the decision-making process, such as goal setting or providing information. This assistance is often necessary for people irrespective of their mental health, but can be particularly important in ensuring people who need support with making decisions are included, and not discriminated against based on their diagnosis. Supported decision-making is considered consistent with the CRPD, and is endorsed by the United Nations Committee on the Rights of Persons with Disabilities. ${ }^{20}$ This same Committee has called for the abolition of substituted decision-making regimes. Substituted decision-making entirely takes away a person's right to make decisions, although decision-makers may be required to involve people in decisions or take their views into account. ${ }^{21}$

In a shared decision-making approach, the decision-making process maintains collaborative partnerships and is person centred, however there is no emphasis on the person having the final say over treatment decisions. ${ }^{22}$ This means shared decisionmaking may be undertaken within a substituted decision-making framework.

Unlike shared or substituted decision-making, supported decision-making, when done properly, allows people the final say over their decisions, including the ultimate right to refuse treatment. ${ }^{23}$ This is obviously inconsistent with the very notion of compulsory treatment, which relies on substituted decision-making, and a tension emerges in attempts to engage in supported decision-making in compulsory mental health settings. ${ }^{24}$ Unlike shared decision-making, which focuses on 'good' health outcomes for consumers, supported decision-making makes no assessment of the outcome, instead it promotes the right to make decisions, whether 'good' or 'bad'. ${ }^{25}$

Representational advocacy is closely linked to supported decision-making, while shared and substituted decision-making are more aligned with best interests approaches. Not all advocacy is representational, with much advocacy undertaken with a view to furthering a person's best interests, rather than based on an interpretation of their will and preferences regarding treatment. An Independent Mental Capacity Advocate acting under s 4 of the Mental Capacity Act (England and Wales) 2005, is an example of a

\footnotetext{
${ }^{18}$ Eades, above $\mathrm{n} 17$.

${ }^{19}$ Gavin Davidson et al, 'Supported Decision Making: A Review of the International Literature' (2015) 38 International Journal of Law and Psychiatry [61].

${ }^{20}$ Committee on the Rights of Persons with Disabilities, General Comment No 1: Article 12: Equal recognition before the law, $11^{\text {th }}$ sess, UN Doc CRPD/C/GC/1 (19 May 2014).

${ }^{21}$ E.g. - Mental Health Act 2014 (Vic) (Austl) s 71.

${ }^{22}$ MB Simmons and PM Gooding, 'Spot the Difference: Shared Decision-Making and Supported DecisionMaking in Mental Health' [2017] Irish Journal of Psychological Medicine 1.

${ }^{23}$ Ibid.

${ }^{24}$ Maylea et al, above $\mathrm{n} 7$.

${ }^{25}$ Simmons and Gooding, above $\mathrm{n} 23$.
} 
best interests advocate, although these roles are required to take into account the person's preferences. ${ }^{26}$

Supported decision-making also means different things to different consumers. Some view themselves as experts in their own recovery, and others identify the need for high levels of support from others. ${ }^{27}$ Using a supported decision-making approach, people must also be allowed to choose who supports them to make decisions, and to delegate decisions to other people, while retaining the right to override them. People must be supported to, and allowed to, make decisions - even about the way in which they are supported in making decisions.

In addition to the support advocates can offer around decision-making and maintaining rights, other studies have identified a preference for advocates to assist in providing information, goal setting and building a person's capacity to self-advocate. ${ }^{28}$ They also prioritised interpersonal qualities in their advocates such as passion, strength and determination, as well as empathy, understanding and cultural appropriateness.

Advocacy in the sense defined above is distinct from, but intrinsically linked with, systemic advocacy, which is focused on system change, rather than representation. This distinction is somewhat confusing, as a 'consumer advocate' may be a consumer who is advocating for system change, or a person who represents on behalf of a consumer. For the purpose of this paper, systemic advocacy is not automatically a function of representational advocacy, although it may be incorporated into some models.

Advocacy also has a long and similarly contested history in other practice contexts, such as homelessness, ${ }^{29}$ older people, ${ }^{30}$ dementia care, ${ }^{31}$ and disability more broadly ${ }^{32}$

${ }^{26}$ Marcus Redley et al, 'Mental Capacity Act (England and Wales) 2005: The Emergent Independent Mental Capacity Advocate (IMCA) Service' (2010) 40(6) The British Journal of Social Work [1812].

${ }^{27}$ Knight et al, above $\mathrm{n} 16$.

${ }^{28}$ Daniel Van der Pluym, 'Consultation Report - Supported Decision Making under the Mental Health Act 2014 - What Consumers Want' (Consultation Report, Independent Mental Health Advocacy, Victoria Legal Aid, 2016); D Barnes, and T Brandon, 'Independent Specialist Advocacy in England and Wales: Recommendations for Good Practice' (Monograph, University of Durham, 2002, http://dro.dur.ac.uk/4356/).

${ }^{29}$ Kirsi Juhila, 'Forms of Advocacy in Social Welfare Work with Homeless Women' (2008) 11(3) European Journal of Social Work [267].

${ }^{30}$ David P Moxley, 'The Logic of Personal Advocacy with Older Adults and Its Implications for Program Management in Community-Based Gerontology' (2004) 27(4) Administration in Social Work [5].

${ }^{31}$ Caroline Cantley, "'Feeling the Way": Understanding How Advocates Work with People with Dementia' (2004) 3(2) Dementia [127]; Moxley, above n 30; David P Moxley, 'The Advocate's Compromise: Strategies and Tactics to Improve the Well-Being of People with Diminished Status' (2014) 8(3) Ethics and Social Welfare [277].

${ }^{32}$ Eilionóir Flynn, 'A Socio-Legal Analysis of Advocacy for People with Disabilities - Competing Concepts of "Best Interests" and Empowerment in Legislation and Policy on Statutory Advocacy Services' (2010) 32(1) Journal of Social Welfare and Family Law [23]; Eilionóir Flynn, 'Making Human Rights Meaningful for People with Disabilities: Advocacy, Access to Justice and Equality before the Law' (2013) 17(4) The International Journal of Human Rights [491]. 
and has been theorised in multiple professional frameworks including nursing ${ }^{33}$ and social work, ${ }^{34}$ where it is seen as a key element of professional practice. This role of advocate within a broader context of care and control, such as in mental health nursing or mental health social work, stems from the assertion that those who have the most contact with people are those who are best placed to advocate for them. ${ }^{35}$ This inevitably leads to notions of best interests advocacy, as these professionals are tasked with both caring for and controlling people, rather than representing their will and preferences. This has led to criticisms that these professionals are adopting the position of advocate not for altruistic reasons, but as a way of bolstering the power and professional status of the professional. ${ }^{36}$ There are obvious conflicts of interest where clinical staff responsible for implementing compulsory treatment also assume the role of advocate. Clinical staff may also owe a legal duty of care to act in the best interests of consumers. ${ }^{37}$ As a result, there is an emerging trend for independent advocates, who sit outside the mental health services and do not experience these conflicts. ${ }^{38}$

\section{VICTORIAN CONTEXT}

In the State of Victoria in south-eastern Australia, people who are subject to compulsory mental health treatment, or at risk of being made subject to it, are eligible for nonlegal advocacy from the Independent Mental Health Advocacy (IMHA). IMHA was launched in 2015, it is state-wide, and is funded by the Victorian Government Department of Health and Human Services (DHHS) and run by Victorian Legal Aid (VLA). IMHA uses a representational advocacy model with an embedded supported decision-making approach, both in the community and in inpatient settings. IMHA is not a statutory body, unlike the Mental Health Advocacy Service in Western Australia, 39 but is part of the broader reform agenda heralded by the new Mental Health Act 2014 (Vic) (Austl.) (the Act). In 2015, the Minister for Mental Health, the Rt Hon Mary Wooldridge MP, noted the role of advocacy;

Funded advocacy was an important addition. Advocacy services are vital to support patients in public mental health services so that they can understand their rights and understand how to exercise them. 40

${ }^{33} \mathrm{~N}$ Carver and J Morrison, 'Advocacy in Practice: The Experiences of Independent Advocates on UK Mental Health Wards' (2005) 12(1) Journal of Psychiatric and Mental Health Nursing 75; Clare Cole, Sally Wellard and Jane Mummery, 'Problematising Autonomy and Advocacy in Nursing' (2014) 21(5) Nursing Ethics [576]; Mick McKeown et al, 'Conflict of Roles: A Conflict of Ideas? The Unsettled Relations between Care Team Staff and Independent Mental Health Advocates' (2014) 23(5) International Journal of Mental Health Nursing [398].

${ }^{34}$ Paul Freddolino, David Moxley and Christine Hyduk, 'A Differential Model of Advocacy in Social Work Practice' (2004) 85(1) Families in Society: The Journal of Contemporary Social Services [119]; Juhila, above n 29; Jane Dalrymple and Jane Boylan, Effective Advocacy in Social Work (SAGE, 2013).

${ }^{35}$ Cole, Wellard and Mummery, above n 33.

${ }^{36}$ Ibid.

${ }^{37}$ Eades, above $\mathrm{n} 17$.

${ }^{38}$ Griffiths, Mendoza and Carron-Arthur, above n 12; Newbigging et al, above $\mathrm{n} 9$.

39 Mental Health Act 2014 (WA) (Austl) s 20.

${ }^{40}$ Victoria, Parliamentary Debates, Legislative Council, 7 May 2015, 1289 (Mary Wooldridge). 
Prior to the introduction of IMHA, limited formal advocacy was provided by consumer advocates with lived experience through the Victorian Mental Illness Awareness Council (VMIAC), and best interests mental health advocacy was and is still provided by Community Visitors through the Office of the Public Advocate, although only in inpatient settings ${ }^{41}$ Informal advocacy, from friends, family and other professionals is also an important part of the advocacy context. ${ }^{42}$ At inception, IMHA was the first funded statewide non-legal representational mental health advocacy service in Australia, although IMHAs have existed in the United Kingdom for some years, ${ }^{43}$ and Western Australia has since introduced a representational model. ${ }^{44}$

\section{THE IMHA MODEL}

IMHA operates across four sites in Victoria, and services are delivered via phone and in person with "outposts" established in inpatient mental health units. Each IMHA team consists of a Senior Advocate, and a number of Advocates. The staff team also includes a Manager, Administration Officer and Senior Consumer Consultant. IMHA is also guided by, and regularly consults with, Speaking From Experience, VLA's consumer advisory group.

IMHA explicitly adopts a representational model, with a focus on recovery and maintaining the rights of people under the Act. The IMHA model consists of a combination of information provision, referral, advocacy or support for self-advocacy, and is informed by the principles in the Act. ${ }^{45}$ These principles include a 'least restrictive' approach; a recovery orientation with a view to full participation in community life; upholding the right of people subject to compulsory treatment to participate in decisions about their assessment, treatment and recovery; and respect for their rights, dignity and autonomy. The IMHA model is also informed by espoused values of integrity, respect, being person-centred, curiosity and reflectiveness, and explicitly adopts a recovery focus. ${ }^{46}$

The remainder of this paper draws on a qualitative study to illustrate this model.

\section{Method}

This study applied a descriptive qualitative research methodology to allow a general inductive approach. Research data was collected through semi-structured interviews of

\footnotetext{
${ }^{41}$ OPA, 'Community Visitors Annual Report 2016-2017' (Office of the Public Advocate, 2017) $<$ http://www.publicadvocate.vic.gov.au/our-services/publications-forms/strategic-plans-and-annualreports/community-visitors-annual-reports/442-community-visitors-annual-report-2016-2017>.

${ }^{42}$ Beaupert et al, above $\mathrm{n} 14$.

43 Karen Newbigging et al, "When You Haven't Got Much of a Voice": An Evaluation of the Quality of Independent Mental Health Advocate (IMHA) Services in England' (2015) 23(3) Health \& Social Care in the Community [313].

${ }^{44}$ Mental Health Act 2014 (WA) (Austl) s 20.

45 Mental Health Act 2014 (Vic) (Austl) s 11.

${ }^{46}$ Maylea et al, above $\mathrm{n} 7$.
} 
approximately 45 minutes duration with a purposive sample of IMHA advocates and stakeholders $(n=13)$. Interview questions focused on three areas:
A. 'Who are the advocates'
B. 'What do the advocates do'
C. 'How do they do it'

The project undertook a qualitative descriptive research approach, ${ }^{47}$ and interviews were undertaken by the chief investigator, who is the senior consumer consultant with IMHA.

A co-produced approach underpinned the research process, led by an experienced consumer consultant supported by mental health academics and the IMHA manager. This was chosen to capture the applied nature and theoretical underpinnings of the model and to give insight into both the context which shaped the model and the ideals it sought to promote. In addition, a number of the participants had a lived experience of using mental health services, and prioritising their voice was an important feature of the approach.

Interviews were conducted at a time and place suitable for the participant and were taped via a digital recorder. Participants were recruited from a variety of backgrounds, classified for the purpose of this analysis as stakeholders, advocates and other IMHA staff. Four stakeholders were from the department of health and human services (DHHS) and were instrumental in the conceptualisation; policy implementation, procurement, and service provider selection process for the development of the IMHA. Two stakeholders were from the Victorian Mental Illness Awareness Council (VMIAC), the peak consumer body in mental health in Victoria, who were involved in the consultation process and advisory committee at the time of the development of the IMHA. Seven were IMHA staff, including five employed as senior advocates or advocates and two staff employed in management and project management roles. Participants were from diverse employment and educational backgrounds, and a number have lived experience of using mental health services.

\footnotetext{
${ }^{47}$ Margarete Sandelowski, 'Whatever Happened to Qualitative Description?' (2000) 23(4) Research in Nursing \& Health [334].
} 
Thematic analysis of the transcripts was carried out by two members of the research team following the phases of conducting thematic analysis; becoming familiar with the data through in-depth reading of the transcripts, generating initial codes, searching for themes, defining and naming themes and producing a report. Initial codes were generated by analysing the transcripts. ${ }^{48}$ The codes were then reviewed to identify any common patterns or variations.

Quotes from participants are distinguished in this paper by a number enclosed in parenthesis.

Ethics approval for this study was obtained through the Swinburne University Human Research Ethics Committee (SUHREC).

\section{Findings}

Four key themes which describe the IMHA model emerged from the data analysis:

1. Privileging the consumer voice

2. Representational advocacy

3. Supported decision-making

4. Enablers and challenges

Each of these themes will be explored using illustrative quotes, with interview identifiers in parentheses.

\section{(1) Privileging the consumer voice}

There was consensus from participants that first and foremost, IMHA exists to serve the consumer - the person wanting or needing the advocacy. The language varied at times from consumer, to person, to client, but there was no doubt whatsoever that it was about the person seeking the service and what that person wanted. This was summed up as "I absolutely serve consumers". (10) One stakeholder expressed it in the following way:

There is a phrase that a friend of mine uses and it fits perfectly here. He is a religious man and he talks about a servant's heart. That, in religious terms, is somebody who lives to assist others, to serve God and other people... with the main responsibility being to put the representation of people at the fore, ....but to, at the end of the day, subordinate that to the goal of the consumer is one of the most important skills there. (6)

There was also consensus that IMHA is funded to serve people who are subject to compulsory treatment under the Act, with a focus on people who are most disadvantaged. Currently advocates are only funded to work with people who are subject to, or at risk of, compulsory treatment, however participants expressed a desire to ensure access to advocacy for all people who access mental health services, including

\footnotetext{
${ }^{48}$ Douglas Ezzy, Qualitative Analysis: Practice and Innovation (Psychology Press, 2002).
} 
formally voluntary people who may be subject to coercion or duress. This IMHA staff member expressed this desire:

... but ideally I would like to think that in some point in time, IMHA's scope would probably ...try to prevent people being subject to involuntary treatment... if advocacy's are involved it's less likely people will be subject to involuntary treatments down the track. (13)

Advocacy was also described in terms of being an independent voice of the person, particularly in settings where the person may feel disempowered. This was linked to a strong feeling from participants of 'having the person's back', 'being on their side' or 'walking alongside the person'. In so doing, they sensed that people felt supported through having somebody on their side who would privilege their voice or support them to voice their own wishes.

\section{(2) Representational advocacy}

All people interviewed were adamant that IMHA's advocacy model is about the person - what they want, what they need, addressing their goals, issues and concerns. Various terminology was used to describe this as: representational advocacy, directions based advocacy or taking instructions from the person, as this stakeholder noted:

... it is really anchored in what the person wants and so the advocates are taking their instruction - if that's the right word - from the person themselves, regardless of what the advocate thinks should or shouldn't be happening. (5)

It was also very clear that representational advocacy at IMHA is not 'best interests' advocacy, and that advocates were not giving advice or offering opinions. Advocates were clear that they were not there to make assessments of a person's decisions:

... not actually making those judgements because that's not our role. There are other professionals in the space we work in, who are doing that all the time and so I think that that's the key thing that defines our model of advocacy. In a way that is different to quite a lot of other advocacy services working in this space. (7)

This theme included two subthemes; a rights-based approach and systemic advocacy.

\section{(2) (a) Rights-based}

The first subtheme was a strong alignment between a representational approach and a rights-based approach, viewing the advocate as the mechanism for upholding rights as expressed by the person. There was some variation from participants on this issue, as some saw rights as informing, underpinning or overarching their approach to advocacy and others saw rights being upheld as a result of the advocacy being in place. This included the work being informed by consumer rights-based frameworks such as the CRPD; advocacy as a right given the theme of supported decision-making in the Act, and others saw it as a check and balance in ensuring services are consumer focused and people's rights are recognised and upheld. In this sense, the advocate was seen to be an accountability mechanism prompting services to give effect to the rights articulated in the Act. There was also some concern expressed that consumer rights may not always be met as intended by the Act. This stakeholder noted the CRPD and 
the Charter of Human Rights and Responsibilities Act 2006 (Vic) (Austl), linking the supporting of rights to systemic change:

There's a number of rights under the disability convention, under our human rights charter, that that [advocate] role facilitates them in and supports the person to be able to enforce their rights and protect their rights. I see those things as connected, intimately connected... I think it's fair to say that through the work that individual advocates do across the state and through the learnings that the program has and feeding back to services of learning, that those things do end up having a systemic effect of improving supported decision making generally across the state, of shifting the power dynamic in the way that the system itself works. While that's not a primary function I think that's a consequence of an effectively working independent advocacy program.

(3)

This clearly demonstrates the function of systemic advocacy as critically related to representational advocacy and emphasising a culture of maintaining rights across the mental health system.

\section{(2) (b) Systemic advocacy}

Participants saw the primary function of IMHA advocates as being individual advocacy - one participant recalled conversations in the establishment phase where the service was being envisaged as individual advocacy. This stakeholder was clear in their understanding of what was and is required:

This was very much individual advocacy and ...there was whole lots of folks saying 'dreadful, 'dreadful. It should be systemic'...But I had a brief that it was never going to do anything else but individual advocacy...the data will be individual but you aggregate that individual data up and look what you've got...and that's what you need if you're going to do systemic advocacy. (8)

Most respondents believed that individual and systemic advocacy were more intricately linked. They saw individual advocacy both as a way to collate issues to raise with services and as a way to change culture and the system more broadly. An IMHA staff member summed this up:

I guess it's all about culture change where you've got incredibly unequal power imbalance between the treating team and a person and I just see advocacy as being like one little thing to just slightly tip that (more up), but it's not the only thing and it will have to be a lot of other systemic change as well. (11)

This is suggestive of the IMHA model as including an oversight function, or perhaps a subversive reform agenda, cloaked in individual advocacy. Systemic advocacy is also a function of VLA more broadly, which is required to take action to minimise the need for individual legal services in the community ${ }^{49}$ One advocate indicated this 'other truth':

Then the other truth from my perspective is actually IMHA is much more about changing a culture than it is about individual outcomes. (10)

This culture change was viewed as a key aspect of systemic advocacy, and a key function of IMHA. Systemic advocacy was seen as valuable and even essential by most participants, although there was some variation in who held ultimate responsibility for leading change. Some saw systemic advocacy as the responsibility of the advocates,

${ }^{49}$ Legal Aid Act 1978 (Vic) (Austl) s 4(d). 
while others saw it as the responsibility of the senior advocates, the IMHA manager, inpatient unit managers or service leaders. One IMHA staff member also identified the importance of privileging the consumer voice when undertaking systemic advocacy within a framework of representational advocacy:

... if we don't have lived experience we should all actually be using the consumer's voice when we actually have conversations about advocacy... so it's not just about the voice in your individual advocacy or at the system level... when you have conversations, that consumer voice should always be paramount. (13)

This need to prioritise the consumer voice (even when the consumer is not present to give instructions) is not a straightforward process. Representing the variety and diversity of consumer voices at the systemic level is another step in the tricky dance of advocacy.

\section{(3) Supported decision-making}

IMHA was established as a mechanism of supported decision-making, in conjunction with a number of other aspects of the Act and the broader reform agenda. This IMHA staff member linked these aspects:

So I guess the vision under the Act was that people who are receiving treatment, whilst they're being treated against their will would still have a role in decisions made about what was happening to them and that in itself is a really challenging idea because the whole underpinning - everything underpinning what the person's situation is, is that they haven't had a say in that decision. (11)

The importance of advocacy within this context was acknowledged by another advocate:

... if you want to have a mental health system that really is committed to supported decisionmaking I think you have to have a service like IMHA because I think the reality is that we don't all start from the same place when we're making those decisions. (7)

Supported decision-making was associated with providing information so that people can make informed choices, and then communicating the preferences of a person with decision-makers. This was conceptualised as being 'behind' the person, not leading them, by giving people space to make their own decisions and trusting them. Participants viewed IMHA as crucial to bringing supported decision-making into mental health services. As this IMHA staff member noted however, service providers did not always demonstrate supported decision-making approaches:

I don't think people have that grasp of what supported decision-making actually is in those settings... It's still substituted decision-making and maybe shared sometimes. (13)

Advocates, on the other hand, demonstrated a high level of nuanced understanding of supported decision-making:

My understanding of what supported decision-making is, is that the person who is using the mental health services should be able to - even in the context of compulsory mental health treatment, should be defining the goals that they want and services should be directed an allocated to the extent that they get them towards those particular goals; that's opposed to maybe best interests, where someone else defines the outcome. (1) 
Supported decision-making was often related to issues of power and control, with a strong sense that it could be used to address the power imbalance between people subject to compulsory treatment and their treating teams. This was also seen to relate to informal coercion, where people might not be formally subject to compulsory treatment but were threatened with it, or where other forms of duress were applied, such as through family members or support services. Advocacy was seen by this advocate to be key in these situations:

Because someone might have mentioned to them that if they don't comply with this or don't do this you'll be put under an order. (2)

Participants noted that this required careful navigation by advocates, to ensure that they did not simply replace one form of coercion with another, as this advocate noted:

... they're really being empowered to make the decision that feels right for them without a kind of pressure or coercion from other sources, then that's when you have to have an advocacy service that's not trying to do any of those things or try and encourage somebody to make the right decision because people have very different perspectives on what the right decision is. I think I see our service as very much part of that supported decision-making framework... (7)

One advocate expressed this as helping the person to discover or articulate their decisions that may have become blurred or difficult to articulate because of the power dynamics at play:

I think people really know what their decisions are, but I think when you're in that situation where you're really compromised and feeling really, really powerless you don't actually trust your own you don't really trust your own voice or your decisions. (9)

In these situations, for this IMHA staff member, the value of an external, independent representational advocate was very clear:

... but that whole relationship is set up in a way that means that the treating team really doesn't have to have much regard to what's going on. Then you have someone independent come in and say 'actually, this is what the person wants and I'm someone from outside this relationship that you're more likely to listen to. (11)

This focus on supported decision-making was not without challenges, as Victorian mental health services are largely entrenched in a substituted or, at best, shared decision-making approaches. The next section highlights some of the enabling factors and identifies the challenges.

\section{(4) Enablers and Challenges}

Broadly, enablers and challenges included the need for role clarity and the critical nature of relationships with consumers, services and carers and families.

Advocates were very clear about their role, but felt that external stakeholders and services were less clear and at times confused about IMHA's role. Role clarity was seen as essential to being able to do the job and making it much easier for the advocates to do their job when people know what they do. Role clarity was also mentioned by one participant in respect to service understanding of the distinction between the IMHA advocates and other professionals who might advocate as part of their role, such as consumer consultants, peer support workers, VMIAC advocates or Community Visitors. 
Advocates are a relatively new part of an already complex system, and for people experiencing mental distress or busy clinicians, confusion was a common challenge. Role clarity was particularly important in light of the relational nature of the IMHA model. This stakeholder neatly captured this challenge:

... of course they won't understand that... it's a new role. It's not the role of someone - an advocate within VMIAC, it is not that role; it is different from that role. There has not been a role like this in Victoria so in the first instance it's going to be, I would think, very hard for the sector to understand what is their role, what can they do and what can't they do? You have all your... peer support workers... consumer consultants... practitioners have their own view of advocates and everyone's got a view of what an advocate is and they're advocates and everyone's an advocate and blah, blah, blah; this is a different role. (8)

The importance of relationships with clinicians and people receiving advocacy was identified as key to successful advocacy. In Victoria, mental health services cannot prevent IMHA advocates from communicating with people, ${ }^{50}$ but they have no other statutory powers. This means that IMHA advocates must rely on positive relationships with clinicians in order to obtain access to consumers and thereby work towards an advocacy outcome. This tension was recognised by this advocate:

I'm also thinking about our relationship, IMHA, to that service, trying to make sure that that's a positive interaction because I think that if we don't kind of have good relationships with mental health services, we can't really do our job... (7)

Relationships with services were also seen as crucial for building awareness of IMHA and promoting the value of advocacy. One major tension identified by participants was the prospect that good relationships with staff might interfere with representational advocacy, if the advocates' own comfort or need to maintain ongoing relationships with services has the potential to compromise the respect for what the person advocating for needed.

This relational role extended to advocacy which involved support people, such as carers and families. This 'tricky dance' was viewed as important, as they were seen as potentially powerful allies or rich support if the consumer wanted them involved, although this was not always the case. Participants identified the need to be upfront about what will and won't be discussed with carers and families, but advocates also have a role in letting people know that the Act supports their right to have families or carers involved in their care. Participants also acknowledged that at times, carers and families members want different things. There were a number of examples of this tension, including one example of a carer complaining that the consumer had a voice that was counter to their 'best interests'. This stakeholder noted:

... they will have their own views about what the patient wants and needs, all of which will assist in understanding how to advocate for this patient. I think there is an important relationship to build there... (12)

The central relational aspect, however, was the relationship with the person accessing advocacy, with participants consistently identifying this as a fundamental element of mental health advocacy.

50 Mental Health Act 2014 (Vic) (Austl) s 16(2)(f); Mental Health Regulations 2014 (Vic) reg 5A. 


\section{DISCUSSION}

In general, the findings from this study highlight the priorities identified in the existing literature. Representational advocacy was viewed as a key way in which the IMHA model worked to privilege the consumer voice and is clearly linked to IMHA's adoption of the supported decision-making principle. This study did not attempt to evaluate the effectiveness of this model, which has been undertaken elsewhere, ${ }^{51}$ however it does articulate the composition of the model. This consistency is unsurprising, as participants entirely consisted of people who had either designed the model or were responsible for implementing it and was not representative of the broader compulsory mental health workforce. This broader mental health workforce would likely have highlighted some critiques of the rights based, legalistic foundations of the representational model, which has been described as leaving those in mental distress as 'dying with their rights on'. ${ }^{.2}$

A best interest approach seeks to justify intervention on the basis of what 'is good' for a person, or finds a middle ground with seeking to do what the person 'would really want', on the basis that the person is not making 'good' decisions. These complexities and objections were not fully explored by the participants of this study, although within the model explored above a number of points arise which have significant implications for practice and future research. These are explored in this section and include; the need for advocates to protect consumers' rights, the inherent power dynamics and the risk of co-option and the role of capacity building and of systemic advocacy in a representational model.

\section{(V) (a) RIGHTS}

The theme of rights was central to the participant's understanding of the advocacy model, however it should be noted that while the Act lays out some clear rights, these rights are commonly not maintained in practice. The rights which compulsory patients are entitled to include the right to receive treatment and assessment in the least restrictive way possible, with voluntary options preferred; ${ }^{53}$ and the right to be involved in and supported to participate in or make all decisions about their assessment, treatment and recovery, ${ }^{54}$ even when this involves a degree of risk. ${ }^{55}$ Advocates indicated that they facilitate this process of participation and supported decisionmaking, by maintaining these rights.

That advocates are necessary to enforce these rights raises a fundamentally problematic tension in compulsory mental health treatment. Why are decision-makers and other clinicians not taking it upon themselves to ensure that each person's rights are upheld? Newbigging et al. write that '... the main purpose of advocacy is

\footnotetext{
51 Maylea et al, above $\mathrm{n} 7$.

${ }^{52}$ Carlos d'Abrera, 'Capacity in Mental Health Law: Are We Heading in the Right Direction?' (2015) 49(9) Australian \& New Zealand Journal of Psychiatry [843]; DA Treffert, 'Dying with Their Rights On' (1973) 130(9) The American Journal of Psychiatry[1041].

${ }^{53}$ Mental Health Act 2014 (Vic) (Austl) s 11(1)(a).

${ }^{54}$ Ibid s 11(1)(c).

${ }^{55}$ Ibid s 11(1)(d).
} 
empowerment, challenging professional paternalism...', 56 however it seems problematic that external advocacy is required to address professional paternalism, which seems an issue professions should be dealing with directly. Until the mental health system adequately responds to this tension, advocates will be a necessary element of the mental health landscape, and could be seen as a method for achieving a mental health service system, which is both rights based and responsive to need.

It was clear that participants understood that advocates were largely successful in involving people in decisions, albeit not always in achieving tangible outcomes. This is consistent with other studies which have highlighted a similar effect. ${ }^{57}$ These studies also identified high levels of satisfaction from people receiving advocacy, despite fundamental rights such as the right to liberty or the right to choose and refuse treatment, being abridged..$^{58}$ This is difficult to quantify ${ }^{59}$ but nevertheless a potential benefit of models such as employed by IMHA.

\section{(V) (b) POWER AND CO-OPTION}

An analysis of the interactions described by the participants is complex, with decision makers, such as psychiatrists, holding statutory power to make decisions, but also the power to reward behaviour, coerce and punish for non-compliance, and power which stems from the expertise and social status of their profession. ${ }^{60}$ Despite this seemingly overwhelming domination of the decision-maker, there are two main ways in which representational advocates identified an ability to exercise power - statutory rights under the Act and, in the absence of statutory powers, relational leverage.

Without statutory powers, the Victorian IMHA model has not been able to rely on legal frameworks to engage mental health services. This is in contrast with the Western Australian model, where advocates have powers to visit persons, inspect any part of a mental health service, make inquiries and copy documents, and where the legislation provides for criminal offences for people who interfere with the exercise of these powers. ${ }^{61}$ Operating in this context, the Victorian IMHA module uses a relational approach, as highlighted by the participants in this study. This relational aspect raises questions regarding the independence of the advocates, who must form enduring professional relationships. This may give rise to their own institutionalisation, as the daily human rights infringements of compulsory mental health assessment and treatment become normalised, or as they are potentially co-opted into the best interest model, which dominates the service system. The necessary but potentially corrupting relationship should be the focus of future study, although there was no sense from the participants that this had become a problem, and other studies have shown that

\footnotetext{
${ }^{56}$ Newbigging et al, above $n$ 43, 314 .

${ }^{57}$ Newbigging et al, above $\mathrm{n} 9$; Maylea et al, above $\mathrm{n} 7$.

${ }^{58}$ Ibid Maylea et al, above n 7; Van der Pluym, above n 28.

${ }^{59}$ Beaupert, above $\mathrm{n} 1$; Maureen C Olley and James RP Ogloff, 'Patients' Rights Advocacy: Implications for Program Design and Implementation' (1995) 22(4) The journal of mental health administration 368.

${ }^{60}$ John RP French Jr. and Bertram Raven, 'The Bases of Social Power.' in Studies In Social Power. (Univer. Michigan, 1959) [150].

${ }^{61}$ Mental Health Act 2014 (WA) (Austl) ss 359, 362.
} 
consumers value their advocates having close relationships with treating teams, as it makes them more effective. ${ }^{62}$ The importance of good relationships was also recognised in the review of the UK IMHA services, which found that close relationships made referral routine, and that:

... effective working relationships reflected a mutual understanding of roles and expectations and the constraints each work under. In these circumstances, professionals drew a clear distinction between independent advocacy and 'best interests', and perceived challenges to professional opinion were met with equanimity. ${ }^{63}$

IMHA have developed a number of strategies to reduce the risk of co-option or institutionalisation, by maintaining independence from the mental health system, including supervision, support and reporting lines outside of mental health services, and consumer guidance from the VLA's advisory group, Speaking From Experience.

\section{(V) (c) CAPACITY BUILDING AND SYSTEMIC CHANGE}

Ideas of systemic reform are explicit in the IMHA model, which includes both building the capacity of people to advocate for themselves, and the explicit focus on systemic advocacy. The first of these features, the focus on capacity building, has both pragmatic and ideological aspects. Every person who is better able to self-advocate is less likely to require advocacy support in the future, reducing their reliance on funded advocacy services and freeing up resources for others. Self-advocacy capacity building is also consistent with the recovery approach, which prioritises the subjective, self-defined, person centred approach to mental health. ${ }^{64}$

In addition, while this study shows no definitive evidence of this, it can certainly be imagined that with an increase in self-advocacy skills across the population of people being compulsorily treated, there arises a corresponding tendency in the clinicians and decision makers who are enforcing compulsory treatment to be receptive to advocacy. In this way, people who are better able to self-advocate themselves hold decision makers to account, supporting a systemic reform agenda. This may make self-advocacy capacity building a potent force in system reform, as well as a pragmatic response to resourcing constraints and a key element of recovery-oriented practice.

However self-advocacy capacity building is not in itself a panacea, as even people who are able to self-advocate well under normal conditions may struggle to do so while in mental distress, or while subject to coercion or force. There is also no use in people feeling empowered to express their own opinions if the service system is unresponsive to their wishes. Users of mental health services have long advocated for more inclusion, 65 and much work remains to be done. IMHA's adoption of a systemic advocacy mandate may go some way to addressing this, representing the voices of consumers in the broader mental health system, in a way that is more difficult for

\footnotetext{
62 Maylea et al, above $\mathrm{n} 7$.

${ }^{63}$ Newbigging et al, above $n$ 43, [321].

${ }^{64}$ Ann McCranie and David Pilgrim, Recovery and Mental Health: A Critical Sociological Account. (Macmillan International Higher Education, 2013).

${ }^{65}$ Nancy Tomes, 'The Patient As A Policy Factor: A Historical Case Study Of The Consumer/Survivor Movement In Mental Health' (2006) 25(3) Health Affairs; Chevy Chase, [720].
} 
services and policy makers to ignore. As identified above, this is not a straightforward process, and further research should explore the nature of systemic advocacy processes within a representational model, however the existence of such advocacy services, and the political willingness to fund them, may signal an important next step on the path to inclusive, compassionate and responsive mental health services.

Conversely, the inclusion of non-legal advocacy within a substituted decision-making regime, such as the Victorian context, may simply act as a veneer of a rights-based approach over what is still a best-interests system. The inclusion of advocates does not make the Victorian scheme compliant with the CPRD. ${ }^{66}$ Participants of this study certainly viewed themselves as shifting the system towards a rights-based approach, however this veneer of rights has the potential to legitimise and perpetuate the substituted decision-making regime it exists within. This is particularly problematic when advocacy is framed, as in this paper, as finding a balance in the tensions between the two irreconcilable approaches - one of which being clearly dominant. This is a question of individual and professional ethics but should be considered in assessments of advocacy services' broader systemic impact.

\section{LIMITATIONS}

This study does not seek complete objectivity, with three of the authors closely involved with IMHA. This approach was chosen to give the greatest depth and understanding of the model presented in this study. As co-produced, consumer led research, this also allowed for each researcher to guide and support the others in their respective areas of expertise.

This study had a small sample size of 13 participants, and the single interview format and relatively short interviews are reflective of resourcing constraints. The interviews were conducted by the Chief Investigator, whose role as Senior Consumer Consultant has no line management responsibilities for any participants, although this position within the organisation and relationship with participants could be expected to introduce some bias. As with any qualitative research, complete objectivity is not the main research goal, and this research design allows for a rounded and critically reflective illustration of the IMHA model.

Furthermore, this is a study of a single, unique, new and still developing program; one example of representative advocacy which can inform the development of other advocacy programs and approaches in other jurisdictions but should not be taken as a definitive example of mental health advocacy.

\section{CONCLUSION}

This paper has focused mainly on the complexities and difficulties associated with representative advocacy, however the main finding of this research is the support this model had from the participants, who saw it as working to address one of the most troubling tensions in mental health care - the perceived need for coercion and

${ }^{66}$ Maylea and Hirsch, above n 5. 
substituted decision-making. Representational advocacy provides a clear, easily transferable and tested framework for engaging in supported decision-making processes with people in the mental health system. This system has so far not succeeded in ensuring peoples' rights are maintained, particularly peoples' rights to be involved in decisions about their treatment, but representational advocacy provides an opportunity to address this basic human right. 